\title{
Socio-Environmental Conflicts in the Limits of Natural Parks in Africa: Characterization and Strategies for the Resolution of Conflicts Between Communities and Wild Animals in Kibale National Park - KNP- Uganda
}

\author{
Diego Higuera Díaz \\ Fundación Interuniversitaria González Bernáldez \\ Universidad Militar Nueva Granada \\ Universidad Nacional de Colombia
}

\begin{abstract}
Kibale National Park - KNP is a park located in the western part of Uganda, where there is a great interest from foreign tourists to visit the chimpanzee (Pan troglodytes) populations that live there. The park is located within a landscape grid, where there are both human settlements of rural populations, where there are small-scale agricultural activities, such as subsistence farming, and large-scale activities such as tea plantations. The KNP's 2008-2017 matrix of records of negative community-wildlife interactions was used for this work. For the study period, it was found that for the five (5) districts that are in the Kibale park environment, $60 \%$ of the incidents were recorded in Kabarole district. As for those of conflicts, approximately 15 wild animals were the ones with whom incidents arose during the study period, 93\% of the cases of incidents were found to be with elephants.
\end{abstract}

Keywords: African studies, wild animal-human conflict

\section{INTRODUCTION}

The interaction between humans and wild animals dates back to the existence of human beings, where there have been positive and negative interactions (Nyhus, 2016). These interactions have been increasing as humans have changed their modes of production, and there has been an increasing growth of human societies, generating scenarios of interactions not only in rural and agricultural areas, but it is already even happening in urban and suburban areas (Anand \& Radhakrishna, 2017). The expansion of areas for agricultural activities is one of the causes of many conflicts between farmers and wild animals worldwide (Mardaraj \& Sethy, 2015). Human-wildlife conflicts have been recorded in many parts of the world, resulting in crop damage, predation of domestic animals and attacks on humans (Torres, et al., 2018).

In several African countries, the heavy dependence of a large proportion of the human population on land for their survival has led to the occupation of places traditionally inhabited by various species of wild animals, including several large mammals, which has led to many sources of conflict between people and wild animals (Hill, et al., 2002). In addition to the presence of these situations, Africa is currently undergoing a rapid transformation (Kansky, et al., 2020).

The areas surrounding natural parks are no exception to these situations of human-wildlife conflict, and clearly the establishment of a natural park has considerable impacts on neighboring communities, and their 
long-term political and economic sustainability depends on managing these relationships properly (Hartter, et al., 2014). Parks and protected areas are generally associated with benefits and related economic values (monetary values) by local residents, because they can improve the quality of the environment, and they can bring benefits in different social and economic aspects including employment (Moswete, et al., 2020). However, in addition to this situation, it should be added that the communities that remain in the surrounding area often accumulate disproportionate costs due to negative incidents that may occur on the edges of the protected area, and conservation challenges are generated by this conformation, although they also benefit from the existence of the protected area (Malajiwa et al., 2015).

These perceptions and attitudes of local residents surrounding protected areas in developing countries can be very wide-ranging (Jelani, 2012, Moswete, et al., 2020).

Knowing these perceptions and attitudes of local people towards protected areas is of great interest, since these will be an essential element for the management and sustainability of the park and each of its components (Hartter et al., 2014). Around the world, different experiences can be found that show that there are several factors that influence negative attitudes towards protected areas such as, human-wildlife conflicts (Bauer, 2003), land claims (Thondhlana et al., 2016), access restrictions and regulations for collecting non-timber forest products (e.g., nuts, wild mushrooms, berries, seeds, medicinal plants and herbs, etc.) and livestock grazing (Bauer, 2003; Gadd, 2005).

Another perception that may exist towards wild animals in some African countries is a non-monetary valuation appreciation of the benefits that wild animals provide especially to pre-colonial communities (Kansky, et al., 2020).

In contrast to some of these situations, traditionally, the establishment of protected areas can involve support for local people, where the establishment of these parks can generate material benefits of foreign exchange, tourism, development and employment (Gabb, 2005). However, this is not a pattern that can be generalized; in some cases there may be parks that are visited by large numbers of tourists, but in others this may not be the case. In the case of forested parks in Africa, annual visitation may be small, so the benefits of the protected area should be more focused on the importance of the ecosystem services provided by the park (Hartter et al., 2014).

Nuisance animal encounters, exposure to zoonotic diseases, injury or even death caused by attacks by large predators have high financial costs to people and society in the form of medical treatments to cure and prevent infections transmitted by wild animals through human contact (Lamarque et al., 2009).

In addition, communities may be economically affected by destruction and damage to property and infrastructure (e.g. crops, orchards, grain storage, water facilities and fences), predation of livestock and transmission of diseases to domestic animals (Hill, et al., 2002). Negative social impacts include additional labor costs, loss of sleep, fear, travel restrictions or loss of pets (Lamarque et al., 2009).

Although there are some common patterns in terms of conflicts between wild animals and the local population, there are some particular elements in the case of KNP that are important to take into account in order to understand the origins of the conflict between wild animals and the local population. In order to understand part of the conflicts around KNP, it is necessary to know the context of the historical moments when there was a strong pressure on wild animals in Uganda. In this scenario, around 1906, the British colonial authorities enacted a hunting ordinance that designated wildlife as crown property and restrictions were enacted to a large extent on so-called "native" hunting (Naughton, et al., 1999). With that claim that all Ugandan wildlife was crown property, they earned huge revenues from ivory and other animal products (Naughton, et al., 1999).

At that time the first Department of Elephant Control was established (1923) which was later renamed "The Ugandan Game Department" (GDA, 1926, 1927, 1931), which provided for the division of Uganda into wildlife and agricultural areas, or in their terms, 'elephant and non-elephant areas'. Great emphasis was placed on controlling and confining wildlife to parks (Naughton, et al., 1999). Several species were subject to control operations, but none received more attention than elephants and even "defensive fronts" were formed, mainly on agricultural frontiers where elephants were "swarming" (Naughton, et al., 1999).

Currently, one of the countries where there are more situations of conflict between humans and wild animals is Uganda (Seoraj-Pillai \& Pillay, 2017, Torres, et al., 2018), the country where KNP is located. In 
this same path, it is worth highlighting that a good part of the conflicts between wild animals and human populations in different African countries have been becoming increasingly evident, where elephants have been one of the species that have generated the greatest economic gains, both as a tourist attraction and as trophies for hunters; However, it is also one of the wild animals with which there have been the greatest conflicts with local populations (Gadd, 2005), in addition to the fact that $84 \%$ of elephant habitat is located outside natural park areas (Blanc et al., 2003) and it is in these areas where conflicts will occur.

A noteworthy aspect of the conflicts between communities and wild animals in relation to KNP is that it has been the focus of more than 30 years of research and has received considerable attention from governmental and non-governmental conservation organizations (Chapman, et al., 2005). Therefore, KNP becomes an interesting example to review the different approaches that have been taken to approach the issue of conflict between wild animals and human societies.

In order to manage the issue of conflict, different interventions have been developed around the world, including technical, cognitive and structural interventions (Hodgson et al., 2020). Within technical interventions, there are interventions directed at the external environment, including physical barriers, changes in land use, changes in species population size or behavior (Baynham-Herd, et al., 2018, Hodgson et al., 2020).

In the category of cognitive interventions, these are aimed at attempting to change negative human behavior towards wildlife and conservation through the provision of information and knowledge, e.g. educational schemes or media campaigns (Baynham-Herd, et al., 2018, Hodgson et al., 2020). Finally, structural interventions seek to modify the deeper social, political and economic contexts in which humanwildlife conflict is found. They include financial instruments to mitigate the economic costs incurred by living alongside wildlife, legislative changes to enforce new rules and behaviors; or social transformation through mediation, stakeholder engagement, and participatory processes (Baynham-Herd, et al., 2018, Hodgson et al., 2020).

According to the previously developed elements, this paper seeks to generally characterize the conflict that has occurred in the period between 2008 and 2017 in KNP, between wild animals and communities settled in the boundaries of the park, identifying some patterns with the wild animals with which there is conflict, as well as identifying which are the districts surrounding KNP where there is more conflict, also reviewing what would be the most appropriate strategies to implement, this paper seeks to generally characterize the conflict that has occurred between 2008 and 2017 in KNP, between wild animals and communities settled in the boundaries of the park, identifying some patterns with the wild animals with which there is conflict, as well as identifying which are the districts surrounding KNP where there is most conflict, also reviewing what would be the most appropriate strategies to implement.

In addition to all the previously mentioned topics, this paper seeks to contribute to the development of South-South cooperation initiatives, since at least in the area of this paper, there is still a lack of development within the framework of this type of cooperation. South-South cooperation has been identified as a key issue for the further development of the South Atlantic (Freres, 2020). Therefore, it is expected that this type of work can contribute to make this great bet a reality.

\section{MATERIALS AND METHODS}

\section{Area of Study}

Kibale National Park (KNP) is located in western Uganda (see map, Appendix 1). Kibale Forest was demarcated in 1932 as a Forest Reserve and elevated to National Park status in 1993 (Struhsaker, 1997). A park renowned for its diverse primate population, KNP ranks fifth in terms of species richness and sixth in overall biodiversity importance among all Ugandan forests (Howard, et al., 2000) (Appendix 2). It is perhaps best known for being home to the largest known chimpanzee community (Hartter, 2007). It is a site that clearly shows agricultural expansion and intensification surrounding protected areas (KNP, 2020).

The park is an ecological island, with dense closed canopy forest, surrounded by a large agricultural population, large tea plantations and a vast network of wetlands and lowland forest fragments (Hartter, 2007). KNP is a mid-elevation tropical moist forest covering approximately $795 \mathrm{~km} 2$ (Hartter, 2007). This 
transitional forest (between lowland rainforest and montane forest) is found at an average elevation of 11101590 meters (Appendix 2).

The people living around the KNP are mainly Batoro and Bakiga ethnic groups (Hartter et al., 2015). The Batoro are natives of the region, while the Bakiga are only immigrants from the densely populated southwest of the country (Hartter et al., 2015) (Appendix 2 and 3). The Bakiga are more intensive farmers who rely more heavily on sales of maize and other food crops than most Batoro (KNP, 2020). There are five districts that share boundaries with KNP, which are Bunyangabo, Kabarole, Kamwenge, Kasese and Kyenjojojo (Appendix 2 and 4).

\section{Data Capture}

The information presented in this paper is part of the database for the period 2008 and 2017 provided by George Owoyesigire of the Ministry of Tourism, Wildlife and Antiquities of Uganda. In addition to this, a tour of some of the KNP boundary areas was conducted in 2018, as part of the projects developed in the area by the African Sustainable Tourism Care Foundation.

The data table processed for the study period includes the date of the occurrence of the conflict event between wild animals and the population, site or village affected, wild animals involved, crops and domestic animals affected, number of people affected, number of users involved and actions taken. Of all the information contained in the matrix within the information that was processed was the presence or absence of conflict situations that had occurred with some of the wild animals reported for the period 2008 and 2017 in KNP environments. This first approach was made in order to see with which wild animals the conflict is sporadic over time and with which there are more frequent conflicts.

In addition to the above, for the study period, the total number of cases of conflicts with wild animals was reviewed for each of the five districts around KNP (Appendix 4). The number of incidents for each of the wild animals with which there was an incident during the study period was also broken down.

In addition to this, a review of the bibliography was made of the strategies that have been used both in the KNP and in other places to reduce conflict situations between wild animals and human communities.

\section{RESULTS AND DISCUSSION}

In KNP and its surroundings (Appendix 4), there are both negative and positive interactions between humans and wildlife. On the one hand, there are negative interactions, which tend to generate conflicts between communities and wild animals. In this scenario of these conflicts, issues of great relevance arise, since these situations can eventually undermine the welfare, health and safety of humans, in addition to presenting economic effects and social costs (Mardaraj \& Sethy, 2015).

In contrast to this scenario of negative interactions, living within the boundaries of a protected area also brings a wealth of positive human-wildlife interactions. These interactions are related to the fundamental role that wild animals play in the dynamics of the ecosystem, which, in turn, underlies a series of ecosystem services or contributions of nature to the rural communities settled in the vicinity of the KNP directly (Hartter et al., 2014), and also brings another large number of contributions to people who do not live in the area. As part of these contributions of nature in relation to the wild animals that inhabit KNP, there is nature tourism, which generates economic activity around the subject (Sarkar et al., 2019).

According to these negative and positive interactions, it is of great importance to ensure that positive interactions are more important and relevant than negative interactions. With this in mind, the following is a characterization of the conflicts that occur in the boundaries of KNP between human communities and wild animals, and then a series of strategies to reduce these conflicts are described. As part of the results found regarding the conflict between wild animals and the different communities living around KNP, it was found that in total, of the five districts bordering KNP (Appendix 4), for the period 2008- 2017, 1775 conflicts were recorded (Table 1), where the District with the highest number of conflicts was Kabarole with $60 \%$ of the cases (Table 1), followed by Kamwenge with 23\% (Table 1), Kyenjojo with 11\%, Kasese district with 5\% (Table 1), 1\% was not associated with any of the districts and Bunyagabo and Kyenjojo had less than $1 \%$ incident reports for this period (Table 1). 
TABLE 1

NUMBER OF INCIDENTS BETWEEN 2008 AND 2017, IN EACH OF THE FIVE DISTRICTS THAT ARE IN THE KNP ENVIRONMENT

\begin{tabular}{lll}
\hline District & Number of Cases & \% \\
\hline Kabarole & 1047 & 60 \\
Kamwenge & 412 & 23 \\
Kyenjojo & 204 & 11 \\
Kasese & 82 & 1 \\
Unknown & 28 & 1 \\
Bunyangabo & 2 & - \\
Total & 1775 & 100 \\
\hline
\end{tabular}

In total for the period under study, the 1775 cases of conflict reported (Table 1), were with approximately 15 wild animals (Table 2), where for most cases the report was made at the species level, but there were also cases where the report was given in a generic way, as was the case of feral cats, and there were other cases where the animal was reported as unknown (Table 2).

Among the animals that were reported were: Elephants (Loxodonta africana), Macaques (Papio cynocephalus), Hippos (Hippopotamus amphibius), Chimpanzees (Pan troglodytes), Lions (Panthera leo), Buffaloes (Syncerus caffer), Wild cats, Wild pigs (Potamochoerus porcus), Leopards (Panthera pardus), Red-tailed monkeys (Cercopithecus ascanius), Crocodiles (Crocodylus niloticus), Foxes (Vulpes sp. ), Jackals (Canis adustus), Vervet monkeys (Chlorocebus pygerythrus) and Pythons (Table 2). According to Mackenzie and Ahabyona (2012), five species of wild animals are found to be particularly associated with crop damage in the KNP boundaries, among which are Macaques (Papio cynocephalus), Wild pigs (Potamochoerus porcus), Red-tailed monkeys (Cercopithecus ascanius), Chimpanzees (Pan troglodytes) and Elephants (Loxodonta africana).

The wild animals with which most conflict was reported in continuity over time were elephants (Table 2 and 3), where of the 10 years in which the conflict data were reviewed, all years there were reports with elephants (Table 2), followed by macaques, where of the 10 years there was conflict in 9 (Table 2), then there were the hippopotamuses where there was conflict in 7 years of the total follow-up time (Table 2), then there were the chimpanzees with 6 years of incidents (Table 2), then there were the chimpanzees with 6 years of incidents (Table 2), There was conflict in 7 years of the total follow-up time (Table 2), then there were the chimpanzees with 6 years of incidents (Table 2). For the other animals identified, the number of years in which there were incidents was less than 3 years (Table 2).

TABLE 2

THIS TABLE RECORDS THE INCIDENTS THAT HAVE OCCURRED BETWEEN 2008 AND 2017 WITH THE DIFFERENT WILD ANIMALS THAT INHABIT KNP

\begin{tabular}{|c|c|c|c|c|c|c|c|c|c|c|c|}
\hline & \multicolumn{10}{|c|}{ Year in which it happened } & \multirow{2}{*}{$\begin{array}{l}\text { Year of } \\
\text { incidents }\end{array}$} \\
\hline & 2008 & 2009 & 2010 & 2011 & 2012 & 2013 & 2014 & 2015 & 2016 & 2017 & \\
\hline Elephants & $\mathrm{x}$ & $\mathrm{x}$ & $\mathrm{x}$ & $\mathrm{x}$ & $\mathrm{x}$ & $\mathrm{x}$ & $\mathrm{x}$ & $\mathrm{x}$ & $\mathrm{x}$ & $\mathrm{x}$ & 10 \\
\hline Macaques & $\mathrm{x}$ & $\mathrm{x}$ & $\mathrm{x}$ & $\mathrm{x}$ & $\mathrm{x}$ & $\mathrm{x}$ & $\mathrm{x}$ & $\mathrm{x}$ & $\mathrm{x}$ & & 9 \\
\hline Hippos & $\mathrm{x}$ & $\mathrm{x}$ & & & & $\mathrm{x}$ & $\mathrm{x}$ & $\mathrm{x}$ & $\mathrm{x}$ & $\mathrm{x}$ & 7 \\
\hline Chimpanzees & $\mathrm{x}$ & $\mathrm{x}$ & $\mathrm{x}$ & $\mathrm{x}$ & $\mathrm{x}$ & $\mathrm{x}$ & & & & & 6 \\
\hline Unknown & $\mathrm{x}$ & $\mathrm{x}$ & & $\mathrm{x}$ & $\mathrm{x}$ & & & & & & 4 \\
\hline Lions & $\mathrm{x}$ & & $\mathrm{x}$ & & & & & & $\mathrm{x}$ & & 2 \\
\hline Buffaloes & $\mathrm{x}$ & & & & & $\mathrm{x}$ & $\mathrm{x}$ & & & & 3 \\
\hline Wild cats & $\mathrm{x}$ & & & & $\mathrm{x}$ & & & & & & 2 \\
\hline Wild Pigs & $\mathrm{x}$ & $\mathrm{x}$ & & & & $\mathrm{x}$ & & & & & 3 \\
\hline
\end{tabular}




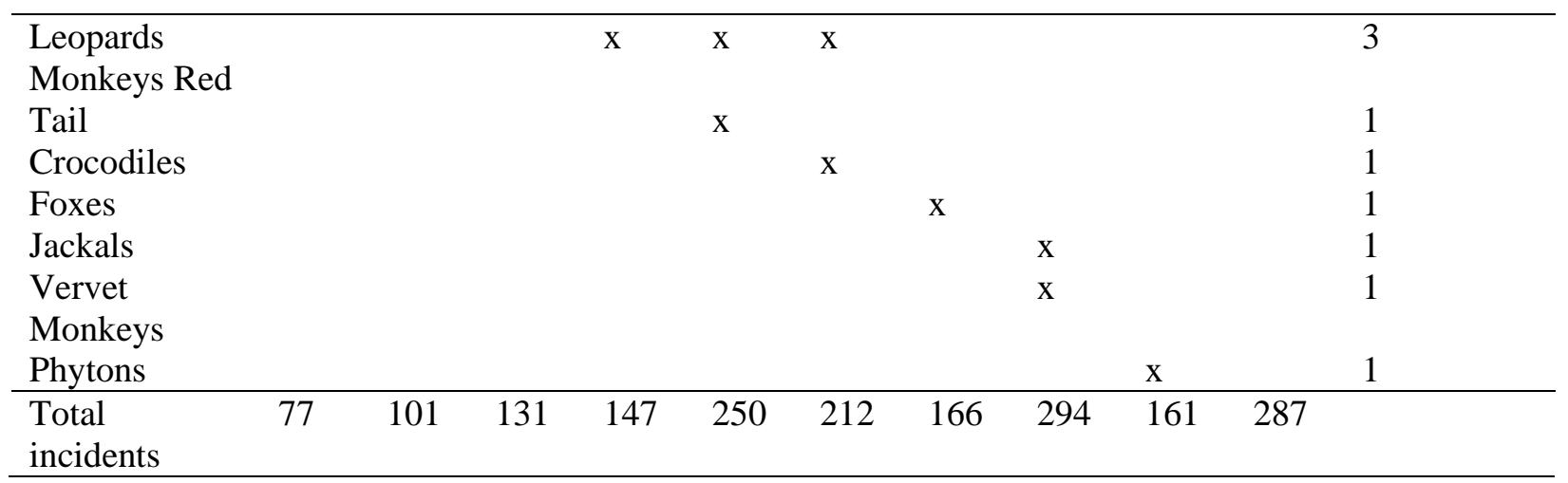

The majority of incidents between humans and wild animals in the KNP at the time of the study involved elephants with $93 \%$ of the incidents (Table 3), these were followed by $6 \%$ of the incidents, where animals such as hippos, chimpanzees, macaques and lions were involved (Table 3), of which $2 \%$ of the incidents were with $2 \%$ of the incidents involved hippopotamuses and for the other species it was around $1 \%$ (Table 3). For the rest of the wild animal species, the percentages were less than $1 \%$ (Table 3).

TABLE 3

\section{LIST OF WILD ANIMALS WITH WHICH INCIDENTS OCCURRED, ALONG WITH THE NUMBER AND PERCENTAGE OF TOTAL INCIDENTS FOR THE PERIOD 2008-2017 IN THE KNP BOUNDARIES}

\begin{tabular}{lll}
\hline Animal & Number of Incidents & $\%$ of incidents \\
\hline Elephants & 1647 & 93 \\
Hippos & 39 & 2 \\
Chimpanzees & 22 & 1 \\
Macaques & 20 & 1 \\
Lions & 20 & 1 \\
Unknown & 8 & - \\
Buffaloes & 6 & - \\
Leopards & 6 & - \\
Wild Pigs & 2 & - \\
Crocodile & 1 & - \\
Fox & 1 & - \\
Jackal & 1 & - \\
Pythons & 1 & - \\
Monkey Red Tail & 1 & - \\
\hline Total & 1775 & 100 \\
\hline
\end{tabular}

The loss of domestic animals such as goats, dogs, chickens and pigs, and agricultural products such as bananas, Irish potatoes, cassava, nuts, coffee, tomatoes, rice, onions, pumpkins, rice, sugar cane, tea plantations, and tobacco plantations were among the damages suffered by residents in the areas near KNP. In other cases no damage was reported and in others no specific damage could be identified. There were more negative impacts on agricultural products than on domestic animals, and there was also less damage to eucalyptus plantations.

In the case of the agricultural fields, problems with wild animals occurred with different products, given that different products are grown in the orchards. The most affected products were maize and bananas. Given the importance of these products for the subsistence of the human communities settled around KNP, the conflict can become more acute (Malajiwa et al., 2015). 
Within the main agricultural land uses around KNP, perennial crops (banana and tea) and other annual crops (beans, ground nuts, maize, potatoes, millet, cassava, Irish potatoes and yams) have been identified (Malajiwa et al., 2015). Beans are generally intercropped with other crops such as; corn, banana and cassava (Nadiope, personal communication, June 2018). In the case of plantain, it is an important staple, grown around farms with other annual crops (Malajiwa et al., 2015).

To understand these figures of conflicts between wild animals and human communities that currently occur in the boundaries of KNP (Table 1, 2 and 3), it is necessary to understand the scenarios that have been occurring at different historical moments in this territory. In the case of conflicts with elephants, which are the wild animals with which most conflict was reported in the period 2008-2017 (Table 3), a background that allows us to understand in part this situation, is related to the fact that, during the 1920s, elephants covered $75 \%$ of Uganda and it is estimated that there were between 20,000 and 30,000 individuals (GDA 1924). Between 1925 and 1958, The Ugandan Game Department killed over 1000 elephants per year, for a total of 31,966, where elephant control campaigns were particularly intense in what is known as the Toro sub-region, which accounts for $29 \%$ of the total (GDA, 1957).

Toro was considered the most difficult sub-region for elephant control in Uganda, particularly in the west (Naughton et al., 1999). This sub-region is now partly made up of Kabarole, Kamwenge and Kyenjojo districts, three of the districts bordering KNP (Appendix 4) where the highest number of incidents are reported in the study period (Table 1), and where indeed elephants are the wild animals with which most conflicts were recorded between 2008-2017 (Table 3). Although quite a few studies have been developed on conflicts with elephants, the conflict still persists with very discouraging consequences for the survival of their populations (Landman, et al., 2008).

Despite the abrupt declines in wild animal populations at the regional level, with these patterns of occupation and transformation of the territory by societies, as well as other anthropic pressures such as overexploitation, which have had a strong impact on wild animal populations, according to Naughton and collaborators (1999), According to Naughton and collaborators (1999), farmers settled less than $1 \mathrm{~km}$ from KNP complained about the loss of their crops due to wild animals, especially those affected by elephants. However, despite the fact that this report was made several years ago, conflict situations continue to occur year after year (Table 2), even though great efforts have been made over the years to reduce the conflict between wild animals and humans in the KNP boundaries (Salerno, et al., 2017).

On the other hand, in contrast to these negative perceptions about KNP wildlife, there are positive perceptions of the people residing around KNP, who are mostly farmers, who are aware that within the ecosystem services or contributions of nature, is the provision of water through rainfall, which is fundamental to their livelihood (Hartter, et al., 2014).

In addition to the provision of water, there are a host of other services or contributions provided by $\mathrm{KNP}$, within which are the provision of resources for fishing, it is an important commercial timber from designated plantation areas, in addition, some of the local communities have traditionally been using the forest as a source of bush meat, building poles, thatching materials, firewood, medicinal products, wild coffee and other non-timber forest products (Chege, et al., 2002) in addition to tourism issues (Sarkar, et al., 2019). Complementary to this positive perception is that regardless of wealth levels, farmers perceive such ecosystem services or contributions from nature, and understand that they depend on them, as crops provide food security and monetary income (Hartter, et al., 2014).

Parallel to this positive perception that farmers living in the KNP boundary zone may have, some things that can contribute to the reduction of conflict are the planned use of the biodiversity within the protected area by the surrounding communities (Blomley, et al., 2010). This is a model that has been found to be very useful for the poorest, as it helps to change perceptions (Blomley, et al., 2010).

In these scenarios it becomes of great importance to work on the perception of the inhabitants towards wild animals, since cases have been found in which people are more tolerant with some wild animals than with others, for example in a study carried out in Namibia, it was found that people were more tolerant with animals such as lions, elephants, and hyenas, but less tolerant with macaques and antelopes (Kansky, et al., 2020). Another factor that has also been found to influence tolerance towards wild animals is the degree of schooling (Torres, et al., 2018). 
This perception of wild animals is an aspect of great relevance, since the management of conflicts with wild animals can be achieved by understanding the tolerance that communities have for different species of wild animals in different areas, which is the basis for initial approaches to solutions to conflict situations (Kansky, et al., 2020). For example, in the case of KNP elephants, which are the wild animals with which most incidents occur (Table 2 and 3), progress should be made in better understanding the effects of elephant density on different levels of biodiversity, both the impact on other species and the impact on the landscape, taking into account how the presence of elephants can help create diversity and maintain habitat heterogeneity (Landman, et al..., 2008, Shaffer et al., 2019), in order to subsequently teach this information to the communities settled in KNP.

Adding to these community perceptions of KNP is the fact that there is a research station at KNP, which generates permanent direct employment for 52 people, and indirectly cascades benefits to about 720 other people residing a few kilometers away (Sarkar, et al., 2019). Additionally, associated with the field research station are other important community benefits, mainly related to health care and education issues (Sarkar et al., 2019). For example, there are some experiences that have been developed with communities living in KNP environments, promoting initiatives where children have spaces for interaction with researchers, so that they learn about ecology and forest biology and, in general, learn to see the KNP project in a positive way (Chapman, et al., 2005). In addition to this, other experiences that have allowed the communities to have a positive perception of the benefits they can obtain by being close to KNP, have been the presence of a mobile clinic that has made occasional visits (Kirumira et al., 2019) or, for example, some women have benefited from the visits of tourists for the sale of their handicrafts (Nadiope, personal communication, June 2018).

KNP has been a park where a great deal of research has been conducted over the years, and scientists from different academic institutions and disciplines have traditionally contributed to conservation efforts by providing information or educating people, thus increasing public awareness and interest in the conservation of each level of biodiversity that coexists in the park (Chapman, et al., 2005). However, although some of the villagers obtain these benefits, both educational and economic, among others, from tourism, these benefits are not sufficiently appreciated and important to integrate them in a better way to the goals of biodiversity protection (Sarkar et al., 2019).

The contributions generated by ecotourism have been identified as having a great impact on the surrounding areas of KNP, especially in terms of income and jobs around the activities generated by this economic activity, where the profits from ecotourism are shared between the protected area and the communities living on the edges of the natural park (Sarkar et al., 2019). However, there are villagers who come to perceive that they receive little from KNP (Kirumira et al., 2019). Although there are different scenarios of agreements with the community, for example, in some cases a percentage of the profits is given to go to projects within the community (Sarkar et al., 2019). Currently there are some initiatives, led by Ugandans, that are looking for tourism where the community perceives that they are being taken into account more, and that they obtain greater benefits from the development of this tourism (Nadiope, personal communication, June 2018).

And although the contributions that tourism generates to reduce the situation of conflict between humans and wild animals should be highlighted, it should also be noted that tourism has brought negative impacts for some wild animals. For example for species such as chimpanzees, which are the animals for which KNP receives the most visits (Hartter, 2007, KNP, 2020), the carrying capacity for their sighting has been exceeded, which has brought affectations to the animals (English \& Manyisa, 2019). On the other hand, regarding the location of chimpanzee populations, it should be added that three of the sites where KNP chimpanzee populations are located (Appendix 1), are close to the boundaries of the three districts where there are more conflicts between wild animals and communities (Table 1; Appendix 1; Appendix 4). However, regarding the issue with conflicts between chimpanzees and the communities settled around KNP, although there were conflict data in several years (Table 2), the numbers of conflict incidence were low (Table 3).

Other negative impacts that can be related to tourism, and other economic and social activities in the area, are related to the issue of wildlife being run over on roads where there is vehicular traffic, especially 
on paved roads around KNP (Cibot, et al., 2015). Among the data available on this issue is that the development of infrastructure and regional development of industry and tourism in Africa has brought a great development of roads and little has been studied on how this affects wild animals (Cibot, et al., 2015).

On the other hand, one of the most striking strategies that has been implemented in KNP to reduce conflicts between wild animals and humans, especially with elephants, which are the wild animals with which most conflicts have been occurring (Table 2 and 3), is the assembly of African bee hives (Apis mellifera scutellata) on the boundaries of KNP (Nadiope, personal communication, June 2018), this in order to persuade especially elephants not to move out of the forested area to agricultural fields (Hodgson, et al., 2020).

The African honey bee has been in decline, apparently due to habitat loss caused largely by humans (Owoyesigire, 2020). So beekeeping project in KNP has distributed 500 bee hives to neighboring communities, of which more than 200 of these hives have been colonized and placed at selected elephant crossing points along the park boundary to create a "bee fence" (Owoyesigire, 2020).

When an elephant hits the structure, it disturbs a hive that sends a ripple effect along the fence to alert others (Hodgson, et al., 2020). The sound of their collective buzzing and stinging, cause elephants to move deeper into the forest, away from farms or crops (King, et al., 2017). The bees have access to the KNP area and flower crops in the surrounding fields that supplement their natural food sources (Owoyesigire, 2020). Added to this, two additional benefits to the establishment of bee colonies in the KNP boundaries are reported, which are, the production of honey, and the benefit to crops from the presence of these pollinators (King, et al., 2017). However, in spite of all the benefits outlined above, the establishment of bee hives is still being experimented with. This is a bet that is still under experimentation, and on which more concrete data should be sought to know in more detail its benefits, as well as to know the potential detriments and the limits that its implementation should have (Owoyesigire, 2020). In addition, research should be conducted to see if the installation of beehives can also persuade other wild animals to move away from the cultivation areas and enter KNP.

Another strategy that has been used for a longer time in KNP environments is to generate buffer areas with tea (Camellia sinensis) crops (Nadiope, personal communication, June 2018). In these buffer areas, what is done is to cultivate species that may have little or no affectation by wild animals, as is the case of tea crops (Babaasa, et al., 2013). These buffer areas should be properly planned by making good use of the land that separates key areas for agricultural production from wildlife production, thus building systems that reduce competition and overlapping interests (Matseketsa, et al., 2019).

This type of crops in a first line, seeks to reduce the areas of conflict with wild animals (Babaasa, et al., 2013). These large monocultures, which are in different places around the KNP, maintain a maximum height of one meter (Nadiope, personal communication, June 2018), and are crops where the presence of surveillance personnel could be observed, so it is likely that these personnel within their work are in charge of warning about the presence of wild animals near the cultivation area. According to what was consulted in the study area, these personnel are in charge of lighting the controlled fire in the points provided for this purpose, when the presence of wild animals is seen nearby.

It has been pointed out that although buffer zones can be costly and long-term actions, the introduction of a buffer zone could be a noble conservation action, as managing conflict on the "hard edges" is an extremely arduous exercise (Matseketsa et al., 2019). Tea plantations, appear to be immune to damage from wildlife incursions, as few wildlife species apparently pass directly through tea, because they do not see it as an attractive site to visit, also the taste of tea is unpalatable to wildlife so they do not generate affectations to it (Majaliwa, et al., 2015).

Currently, tea cultivation activities are being coordinated through the National Agriculture Advisory Services Program (NAADS) started in 2001, who promoted tea cultivation as an alternative to coffee cultivation, especially in areas where coffee had been affected by wilt (Ezra, et al., 2014). NAADS was successful in propagation and distributed 23 million clonal seedlings to smallholders in Kabale, Bushenyi, Kabarole, Hoima, Kyenjojo and Kibale. Such activities are highly correlated with the expansion of tea production to 50,000 tons in 2010 (Ezra, et al., 2014). 
Something to consider is that although this is a government initiative that may be contributing to reduce the conflict between wild animals and communities, in this type of strategy, economic growth expectations may be prioritized without taking into account the initial objective for which they were proposed. A poor implementation of this strategy can increase socio-environmental conflicts between wild animals and communities, since by generating economic and social expectations through the expansion of this type of activities, the areas of monocultures would increase, which would generate pressure on wild animals to move to other places, either to obtain resources, or because these plantations require greater amounts of resources such as water (Ezra, et al., 2014). In addition, large extensions of tea plantations generate soil erosion and ecosystem degradation (Majaliwa et al., 2010).

Some points to take into account when analyzing the implementation of this type of strategy are through a review of land use. In the case of Kabarole district, which was the KNP area where the highest number of conflicts occurred in the study period (Table 1), in the western part of this district, it is found that it is a very suitable area for tea crop production, the southern part is very suitable for maize cultivation and the northern part is very suitable for banana cultivation, and the central part of Kabarole is very suitable for both banana and maize (Majaliwa et al., 2015). Among the recommendations that have been made to take advantage of these potential land uses, and that this in turn helps to reduce the conflict, is the establishment of buffer zones of $3.5 \mathrm{~km}$ of tea and eucalyptus plantations, where the use of the type and number of pesticides and fertilizers to be applied is controlled (Majaliwa, et al., 2015).

These are just some of the main strategies identified that can be developed, strengthened or adjusted to the conflict situations that are occurring in KNP, however, there are a large number of other strategies that have been developed in the KNP boundaries, some of which are presented in Appendix 6, in order to give more elements to understand that the solutions must be generated in a comprehensive manner to continue decreasing the conflict without harming wild animals.

Although conflict with wild animals remains as one of the problems faced by the communities settled in the boundaries of the Park, studies show that for some of the people living in the KNP boundaries, the main problem they face is crop theft $(42 \%)$, diseases $(17 \%)$, reduced land for agriculture (12\%), noise $(12 \%)$, reduced land for settlement (8\%), primates blocking pathways for children (3\%), human conflicts with wildlife (3\%), and bad roads (3\%) (Tuhaise, 2018) (Tuhaise, 2018). Accordingly, although there are still a high number of conflicts between wild animals and communities (Table 1), the various actions that have been taking place have possibly helped to ensure that conflicts with wild animals are not perceived as one of the main problems that local people have to face.

In addition to these perceptions, it has been found that among the main risk perceptions that the inhabitants of this area have about what could generate conflict situations are: population growth, forest loss and climate change (Hatter, et al., 2016) (Appendix 5). Among the pressures identified that KNP could suffer due to population growth is the increase in crop areas; in terms of climate, the disadvantages identified are that there is a variable climate and that the amount of rainfall decreases; in terms of health issues, an increase in diseases was identified; and all of this is associated with population growth and forest loss (Hatter, et al., 2016) (Hatter, et al., 2016).

As part of the problems in the area around KNP, people identify climate variability as something that will further exacerbate food insecurity and disease for local residents (Hatter, et al., 2016). They also see how this variability will lead to wildlife moving out of protected areas, causing them to move into alternate areas in response to climate change, but this will be constrained by human settlement, resulting in increased human-wildlife conflict at protected area boundaries, and potentially more zoonotic disease transmission (Hatter, et al., 2016).

In this scenario, where the conflict between wild animals and the population settled on the KNP boundaries is still present (Table 2), it is of vital importance to work on different strategies and at different levels, where as part of the strategies to be implemented the work should be focused on persuading wild animals to leave the KNP, so it becomes a priority to monitor the effectiveness of the strategies and mechanisms that have been implemented, as well as to evaluate the investment that is required. In terms of working at different levels, it is necessary to work with the local population, tourism promoters, plantation owners, and local and national governments, among others. 
In this task, one of the protagonists that has had more prominence in working on the different strategies and at different levels, has been the KNP administration, since it has the responsibility to protect wild animals, but this puts them in different situations of conflict, especially with local communities (Nadiope, personal communication, June 2018). In this scenario, from the different instances, in this search for strategies to reduce the conflict, we should always be looking for the best articulation between the different actors that in one way or another have a relationship with the territory, so that the work carried out by the KNP administration can be more effective and well received.

Accordingly, the strategies to be implemented should be cross-cutting and complement each other. Local people are often sensitized about animal behavior and its conservation value, so it is important that they are taken into account in the selection of the strategies to be implemented, as well as in the design, implementation and maintenance of interventions to reduce and avoid conflict with wild animals. This is of utmost importance since interventions that have been implemented without the participation of the local community have failed, most of the time (Nadiope, personal communication, June 2018).

\section{CONCLUSIONS}

The KNP administration, along with the participation of the regional governments and the national government, needs to be permanently accompanying the communities settled around KNP, where education and permanent sensitization sessions can be carried out regarding the implications of living in the vicinity of a natural park that seeks to protect the wild animals that live there. In this scenario, there should also be permanent coordination between the actions taken by the KNP administration to reduce the conflict, as well as the involvement of the communities in the installation and maintenance of the measures that are put in place.

Taking into account that Kabarole is the district where most cases of conflict were reported during the period of this study, it should be sought to establish which are the routes and points of greatest conflict in this district, and once this has been identified, it should be sought which are the most successful strategies and mechanisms that have been established in other districts or in other places with similar dynamics, in order to seek to reduce the number of incidents.

Given that the wild animals with which there is still most conflict are elephants, communication strategies should be sought to generate a positive impact in the communities regarding the role of these animals in the ecosystem, such as generating material that shows what is lost with each elephant that disappears. To this end, it is important to develop strategies that target specific audiences and raise awareness of the conflict issues.

It is important to understand the economic dynamics that are occurring in the KNP boundaries, in order to foresee situations that could become pressures that could potentially increase the conflict with wild animals in the KNP boundaries.

It is important to strengthen the evidence on the role of tea cultivation around the issue of conflict between wild animals and human communities in KNP, in order to seek how to establish the best practices for this crop, benefiting both economic alternatives for the community and the survival of wild animals. For this, both positive and negative impacts must be identified. Once this has been determined, differential markets can be sought that favor the consumption of this tea, always bearing in mind that the main objective is to contribute to the reduction of the conflict and maintain benefits for the wild animals and the communities.

One of the most promising options that has been explored to reduce the conflict with KNP's wild animals has been the installation of beehives, however, there is still much work to be done to ensure sustainable results, increase the honey market, seal the remaining gaps in the park boundaries, provide more training for the community, and include beekeeping in the annual operational plans for sustainable conservation in the area, in addition to this it is required to review the negative impacts that can be produced by the installation of these hives.

It is important that local people continue using traditional construction materials, as well as encouraging the use of native species, especially vegetables, to meet the different needs they may have, because if they 
start using new materials that are not from the area, they will have to buy them, and in many cases the rural communities in these areas do not have sufficient or permanent income to be able to build complete houses with materials such as cement, bricks, zinc roofing tiles, among others. This means that if they use traditional materials, they would not be incurring in expenses for foreign materials, which would help them not to lose contact with the environment and see the additional benefits that having a park in a good state of conservation can bring them. For example, palm roofs are a very good alternative for the houses, in addition to mud and wood wall construction, along with mud floors, among other materials that can also contribute. In addition, this type of housing, if done in a planned manner and in conjunction with the communities, can have an added value for tourism.

Try to recover some of the cultural traditions that the communities have lost that are related to nature, such as traditional medicine, especially those associated with native plants found in KNP, as well as ancestral rituals that are related to positive attitudes towards wild animals and plants of KNP, among others, since to the extent that different elements of cultural traditions are strengthened, respect and appreciation for their environment is also strengthened.

\section{ACKNOWLEDGEMENTS}

I thank the Africa Sustainable Tourism Care Foundation, who welcomed me in 2018 to participate in one of the projects they have been working around KNP, related to the issues of wildlife-human conflict at the KNP edge, I thank George Owoyesigire, Principal officer of the wildlife office of the Ministry of Tourism , Wildlife and Antiquities of Uganda whom I met in 2016 at the CITES and livelihoods meeting in Albertinia, South Africa, and who with the experiences shared in 2016 within the framework of the meeting, motivated me to participate in 2018 in this project in Uganda, and also generously shared with me the conflict matrices around KNP for the period (2008-2017). To my friend Lee Vasey, with whom we were sharing the different spaces in the development of the project. To Timothy Nadiope who shared with me a lot about the Ugandan culture and to James Nadiope, project leader of the Africa Sustainable Tourism Care Foundation who accompanied me in the different tours around KNP and who provided me with permanent information about the work being done to reduce the conflict between communities and wild animals in the boundaries of KNP. Thanks to Tatiana and Aluna for all the support to make the trip and the support to write the document.

Translated \& edited by American Publishing Services (https://americanpublishingservices.com/).

\section{REFERENCES}

Anand, S., \& Radhakrishna, S. (2017). Investigating trends in human-wildlife conflict: Is conflict escalation real or imagined? Journal of Asia-Pacific Biodiversity, 10, 154-161.

Babaasa, D., Emmanuel, A., \& Bitariho, R. (2013). Human-wildlife conflict management: Experiences and lessons learned from the greater Virunga Landscape. Institute of tropical forest conservation Mbarara University of Science and Technology, Uganda.

Bauer, H. (2003). Local perceptions of Wazha National Park, northern Cameroon. Environ. Conserv., 30, $175-181$.

Baynham-Herd, Z., Redpath, S., Bunnefeld, N., Molony, T., \& Keane, A. (2018, April). Conservation conflicts: Behavioural threats, frames, and intervention recommendations. Biological Conservation, 222, 180-188.

Blanc, J., Thouless, C.R., Hart, J.A., Dublin, H.T., Douglas-Hamilton, I., Craig, C.G., \& Barnes, R.F.W. (2003). African Elephant Status Report 2002: An update from the African Elephant Database 304. IUCN/SSC African Elephant Specialist Group, Gland, Switzerland and Cambridge, UK.

Blomley, T., Namara, A., McNeilage, A., Franks, P., Rainer, H., Donaldson, A., . . . Infield, M. (2010). Development and gorillas? Assessing fifteen years of integrated conservation and development in south- western Uganda, Natural Resource Issues No. 23. IIED, London. Retrieved November 10, 2012, from http://pubs.iied.org/14592IIED.html?k=bwindi 
Bortolamiol, S., Cohen, M., Potts, K., Pennec, F., Rwaburindore, P., Kasenene, J., . . . Vignaud, Q.K. (2014). Suitable Habitats for Endangered Frugivorous Mammals: Small-Scale Comparison, Regeneration Forest and Chimpanzee Density in Kibale National Park, Uganda. PLoS ONE, 9(7), e102177. doi.org/10.1371/journal.pone.0102177

Byrne, M., Witkowski, E., \& Kalibbala, F. (2011). A review of recent efforts at biological control of Caesalpinia decapetala (Roth) Alston (Fabaceae) in South Africa.

Chapman, C., Struhsaker, T., \& Lambert, J. (2005). Thirty Years of Research in Kibale National Park, Uganda, Reveals a Complex Picture for Conservation. International Journal of Primatology, 26(3).

Chege, F., Onyango, G., Drazu, C., \& Mwandha, S. (2002). Kibale and Semuliki conservation and development project. Evaluation Report.

Cibot, M., Bortolamiol, S., Seguya, A., \& Krief, S. (2015). Chimpanzees facing a dangerous situation: A high-traffic asphalted road in the Sebitoli area of Kibale National Park, Uganda. Am J Primatol. DOI: 10.1002/ajp.22417

English, P., \& Manyisa Ahebsa, W. (2019). Tourism product development in Uganda, A strategic stance. Final Report. IGC. International Growth Centre. F-19043-UGA-1.

Ezra, M., Lakuma, C., \& Guloba, M. (2014). Uganda's Tea sub-sector: A comparative review of trends, challenges and coordination failures. Research series no. 119.

Freres, C. (2020). Cooperación Sur-Sur: Un elemento clave para el despegue del Atlántico Sur. Revista CIDOB d'Afers Internacionals, (102-103), 125-146.

Gadd, M. (2005). Conservation outside of parks: Attitudes of local people in Laikipia, Kenya. Environ. Conserv., 32, 50-63.

Gloriose, U. (2019). Community Perceptions of Human-wildlife Conflicts and the Compensation Scheme Around Nyungwe National Park (Rwanda). International Journal of Natural Resource Ecology and Management, 4(6), 188-197

Hartter, J. (2007). Landscape change around Kibale National park, Uganda: Impacts on land cover, land use, and livelihoods. A dissertation presented to the graduate school of University of Florida in partial fulfillment of the requirements for the degree of Doctor of Philosophy. University of Florida.

Hartter, J., Ryan, S., MacKenzie, C., Goldman, A., Dowhaniuk, N., Palace, M., . . Chapman, C. (2015). Now there is no land: A story of ethnic migration in a protected area landscape in western Uganda. Population \& Environment, 36(4), 452-479. doiorg.ezproxy.umng.edu.co/10.1007/s11111-014-0227-y

Hartter, J., Solomon, J., Ryan, S.J., Jacobson, S.K., \& Goldman, A. (2014). Contrasting perceptions of ecosystem services of an African forest park. Environmental Conservation, 41(4), 330-340. doi:10.1017/S0376892914000071

Hartter, J.N., Dowhaniuk, N., MacKenzie, C.A., Ryan, S.J., Diem, J.E., Palace, M.W., \& Chapman, C.A. (2016). Perceptions of risk in communities near parks in an African biodiversity hotspot. Ambio, 45, 692-705. doi: 10.1007/s13280-016-0775-8

Hill, C., Osborn, F., \& Plumptre, A.J. (2002). Human-Wildlife Conflict: Identifying the problem and possible solutions. Albertine Rift Technical Report Series Vol. 1. Wildlife Conservation Society.

Hodgson, I., Redpath, S., Sandstrom, C., \& Biggs, D. (2020). The state of knowledge and practice on Human-Wildlife conflicts. Luc Hoffmann Institute.

Howard, P., Davenport, T., Kigenyi, F., Viskanic, P., Baltzer, M., Dickinson, C., . . Mupada, E. (2000). Protected area planning in the tropics: Uganda's national system of forest nature reserves. Conservation Biology, 14(3), 858-875.

Jelani, J.O. (2012). Local people's perception on the impacts and importance of ecotourism in Sabang, Palawan, Philippines. Procedia Soc. Behav. Sci., 57, 247-254.

Kansky, R., Kidd, M., \& Fischer, J. (2020). Does money "buy" tolerance toward damage- causing wildlife? Conservation Science and Practice. 
King, L.E., Lala, F., Nzumu, H., Mwambingu, E., \& Hamilton, I.D. (2017). Beehive fences as a multidimensional conflict-mitigation tool for farmers coexisting with elephants. Conservation Biology. DOI: 10.1111/cobi.12898

Kirumira, D., Barangab, D., Hartter, J., Valenta, K., Tumwesigye, C., Kagoro, W., \& Chapman, C.A. (2019). Evaluating a Union between Health Care and Conservation: A Mobile Clinic Improves Park-People Relations, Yet Poaching Increases. Conservation and Society, 17(1), 51-62.

KNP, Kibale Forest National Park. (2020). Retrieved from https://www.kibaleforestnationalpark.com/

Lamarque, F., Anderson, F., Fergusson, R., Lagrange, M., Osei-Owusu, Y., \& Bakker, L. (2009). Humanwildlife conflict in Africa Causes, consequences and management strategies. FAO Forestry Paper, 157.

Landman, M., Kruger, L., \& Owen-Smith, N. (2008). Effects of elephants on ecosystems and biodiversity (Chapter 3).

Laudati, A.A. (2010). The encroaching forest: Struggles over land and resources on the boundary of Bwindi Impenetrable National Park, Uganda. Society and Natural Resources, 23, 776- 789. In B. Dennis, Akampulira, \& B. Robert, Human-wildlife conflict management: Experiences and lessons learned from the greater Virunga Landscape. Institute of tropical forest conservation Mbarara University of Science and Technology, Uganda.

MacKenzie, C. (2012). Trenches like fences make good neighbours: Revenue sharing around Kibale National Park, Uganda. Journal for Nature Conservation, 20, 92-100.

Mackenzie, C.A., \& Ahabyona, P. (2012). Elephants in the garden: Financial and social costs of crop raiding. Ecological Economics, 75(C), 72-82.

Majaliwa, J.G.M., Ratemo, S., Zizinga, A., Mugarura, M., Wafula, S.D., Tunywane, I., . . Kaahwa, R. (2015). Suitability of major agricultural land uses around Kibale National Park. African Journal of Agricultural Research. https://doi.org/10.5897/AJAR2014.9197

Majaliwa, J.G.M., Twongyirwe, R., Nyenje, R., Oluka, M., Ongom, B., Sirike, J., . . Barasa, B. (2010). The Effect of Land Cover Change on Soil Properties around Kibale National Park in South Western Uganda. Applied and Environmental Soil Science. doi: 10.1155/2010/185689

Mararakanye, N., Magoro, M.N., Matshaya, N.N., Rabothata, M.C., \& Ncobeni, S.R. (2017). Railway side mapping of alien plant distributions in Mpumalanga, South Africa. Bothalia, 47(1).

Mardaraj, P.C., \& Sethy, J. (2015). Human-Wildlife Conflict: Issues and Managements. Biodiversity Conservation, Research and Management.

Matseketsa, G., Muboko, N., Gandiwa, E., Kombora, D., \& Chibememe, G. (2019). An assessment of human-wildlife conflicts in local communities bordering the western part of Save Valley Conservancy, Zimbabwe. Global Ecology and Conservation, 20.

Moswete, N., Thapa, B., \& Darley, W. (2020). Local Communities' Attitudes and Support Towards the Kgalagadi Transfrontier Park in Southwest Botswana. Sustainability, 12, 1524.

Naughton, L., Robert, R., \& Treves, A (1999). The social dimensions of human-elephant conflict in Africa: A literature review and case studies from Uganda and Cameroon. A Report to the African Elephant Specialist, Human-Elephant Task Conflict Task Force, of IUCN, Glands, Switzerland. Game Department Achieves of Uganda. Property of the Uganda Wildlife Authority, Ministry of Tourism and Wildlife, Government of Uganda, Kampala, Uganda.

Naughton, L., Rose, R., \& Adrian, T. (1999). The social dimensions of human- elephant conflict in Africa: A literature review and case studies from Uganda and Cameroon. A Report to the African Elephant Specialist, Human-Elephant Task Conflict Task Force, of IUCN, Glands, Switzerland.

Nyhus, P. (2016). Human-wild conflict and coexistence. Annu. Environ. Resour., 41, 143-171.

Owoyesigire, G. (2020). Bees, Elephants, and People. Berkeley, International \& Executive Programs.

Salerno, J., Chapman, C.A., Diem, J.E., Dowhaniuk, N., Goldman, A., MacKenzie, C.A., . . Hatter J. (2017). Park isolation in anthropogenic landscapes: Land change and livelihoods at park boundaries in the African Albertine Rift. Regional Environmental Change, 18(3). doi:10.1007/s10113-017-1250-1 
Sarkar, D., Chapma, C., Valenta, K., Angom, S., Kagoro, W., \& Sengupta, R. (2019). A tiered analysis of community benefits and conservation en engagement from the Makerere University Biological Field Station, Uganda. The Professional Geographer, 71(3), 422-436. DOI:10.1080/00330124.2018.1547976

Schroth, G., Fonseca, G., Harvey, C., Gascon, C., Vasconcelos, H., \& Izac, A-M. (2004). Agroforestry and biodiversity Conservation in Tropical Landscapes. Island Press.

Seoraj-Pillai, N., \& Pillay, N. (2017). A Meta-Analysis of Human-Wildlife Conflict: South African and Global Perspectives. Sustainability, 9, 34.

Shaffer, L.J., Khadka, K.K., Van Den Hoek, J., \& Naithani, K.J. (2019). Human-Elephant Conflict: A Review of Current Management Strategies and Future Directions. Front. Ecol. Evol., 6, 235. doi:10.3389/fevo.2018.00235

Silajander, M., Kuronen, T., Johansson, T., Munyao, M.N., \& Pellikka, P.K.E. (2020). Primates on the farm - spatial patterns of human-wildlife conflict inforest- agricultural landscape mosaic in Taita Hills, Kenya. Applied Geography, 117.

Struhsaker, T.T. (1997). Ecology of an African Rain Forest: Logging in Kibale and the Conflict Between Conservation and Exploitation. Gainesville, Florida, USA: University Press of Florida.

Thondhlana, G., Cundill, G., \& Kepe, T. (2016). Co-management, land rights and conflicts around South Africa's Silaka Nature Reserve. Soc. Nat. Resour., 29, 403-417.

Torres, D., Oliveira, E., \& Alves, R. (2018). Conflicts Between Humans and Terrestrial Vertebrates: A Global Review. Tropical Conservation Science, II, 1-15.

Tuhaise, M. (2018). Local community perceptions and contributions to primates conservation around wildlife reserve areas in Uganda: A case study of Kibale National Park, Kabarole District. Undergraduate dissertation repository. Makerere University. Retrieved from http://hdl.handle.net/20.500.12281/4960 


\section{APPENDIX 1: LOCATION OF KIBALE KNP NATIONAL PARK}

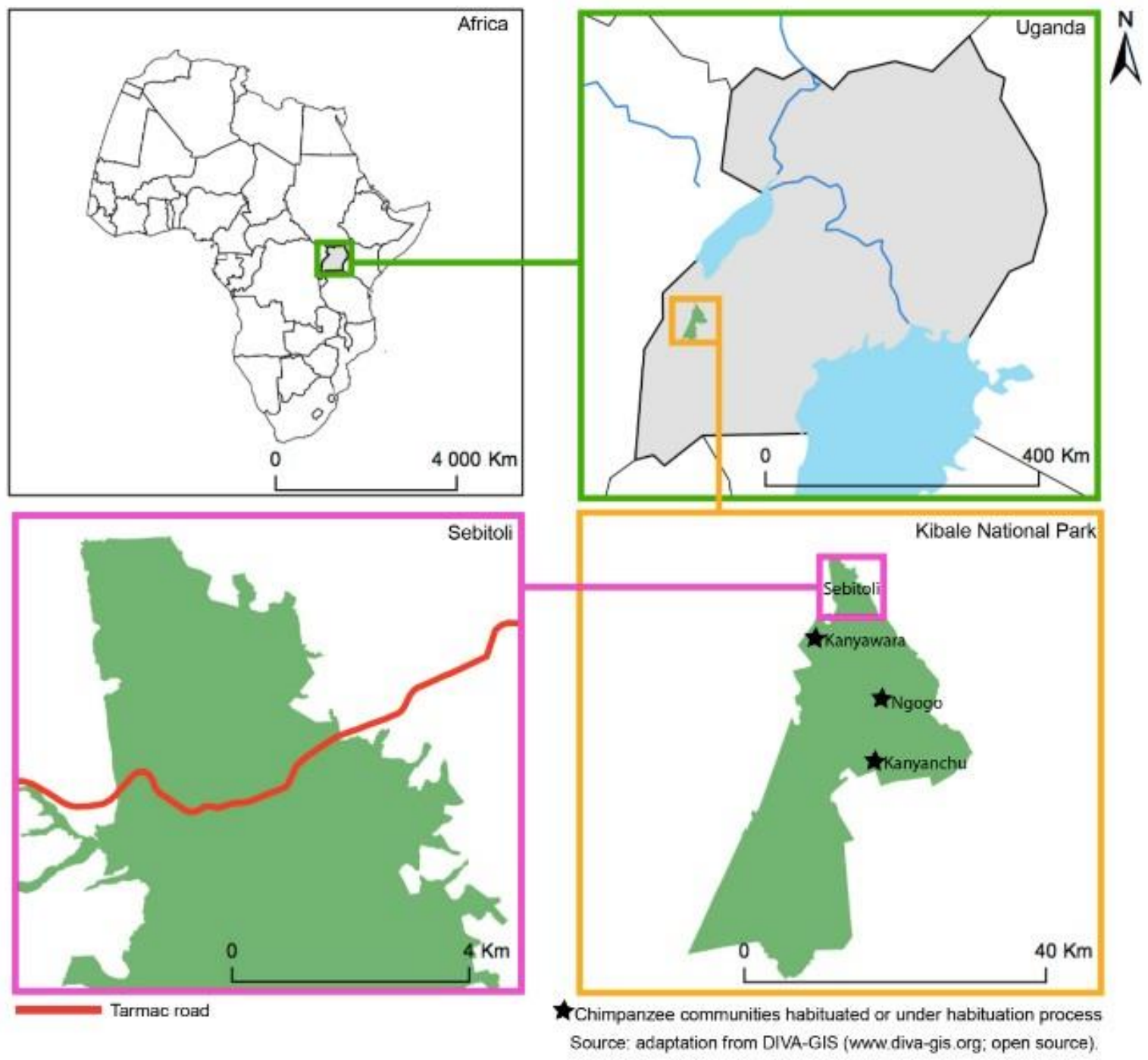

Figure taken from Bortolamiol, et al., 2014.

\section{APPENDIX 2: DETAILS OF THE STUDY AREA}

\section{Climatic Conditions}

The wettest area of KNP is in the north, where there is an average annual rainfall of $1700 \mathrm{~mm}$, mainly during March-May and September-November. The temperature is warm throughout the year, with an annual average between 14 to $27 \mathrm{C}^{\circ}$. Temperatures are highest (and rainfall is lowest) in the south, where the terrain falls on the scorching rift valley floor and the forest provides the path to open grasslands (KNP, 2020).

\section{Other Nearby Natural Areas}

The southern KNP borders Queen Elizabeth National Park, and, collectively these preserved areas support a $180 \mathrm{~km}$ long wildlife migration corridor extending from the remote southern sector of Queen Elizabeth National Park at "Ishasha", north to Kibale at "Sebitoli" (Appendix 2). The park is located near 
the tranquil Ndali Kasenda crater area close to the Queen Elizabeth, Rwenzori Mountains and Semuliki National Parks, along with the Toro-Semliki Wildlife Reserve (KNP, 2020).

\section{Kibale Forest Wildlife and Flora}

The varied altitude of KNP supports different varieties of habitat, ranging from moist evergreen forest (tropical rainforest) along the Fort Portal plateau, then through tropical dry forest (moist semi-deciduous), and then up to forest and savanna along the rift in the valley (KNP, 2020).

In the central part of KNP, around Kanyanchu, the high forest consists of a mixture of evergreen and deciduous trees, with evergreen species being dominant (KNP, 2020). The vegetation rises to over 55 meters and establishes a semi-closed canopy of with stratified canopy massing (KNP, 2020). With shade tolerant herbs, a variety of ferns, shrubs and broad-leaved grasses, undergrowth is sparse. A total of 351 tree species have been recorded in the park (KNP, 2020).

\section{Settlements Around Kibale}

The Batoro take great pride in the ethnic heritage of the Toro Kingdom, an offshoot of the ancient kingdoms of the Great Lakes region of Africa (KNP, 2020). The king (Omukama) and the kingdom embody the traditional along with the cultural values of the Batoro. The immigrants (Bakiga) still retain their culture and tradition as expressed in their dance, folklore and language (KNP, 2020).

With the peace of Uganda in 1987, Ugandan civil society began to rebuild and the national government approved biodiversity conservation, in 1993, the Kibale Forest Reserve was redesigned and a $760 \mathrm{~km} 2$ national park was formed, and over 30,000 residents inhabiting the area adjacent to the Kibale corridor were forcibly evicted and resettled elsewhere (Naughton, et al., 1999).

There are different types of settlements around KNP, which differ in altitude, ethnic composition, settlement and land use history (Hartter, et al., 2014). The western area is predominantly occupied by the Batoro ethnic group, which began settling in the area near KNP in the early decades of the 20th century (Hartter, et al., 2014). The eastern part is mainly occupied by Bakiga households, who migrated to the area in the 1950s and 1970s as part of a resettlement scheme from the heavily populated regions of southwestern Uganda (Hartter, et al., 2014).

The eastern side, has some tourist attractions (e.g., chimpanzee tracking and community wetlands) and accommodation, and some seasonal employment opportunities throughout the park. The southwest of the park, where there is hardly any tourism infrastructure, is a mix of mainly Bakonjo (fewer intensive farmers such as Batoro) and Bakiga and some Batoro (KNP, 2020). 


\section{APPENDIX 3: MIGRATION OF THE BAKIGA AND AREAS AROUND THE PARK WHERE THE BAKIGA AND BATORO ARE CURRENTLY SETTLED}
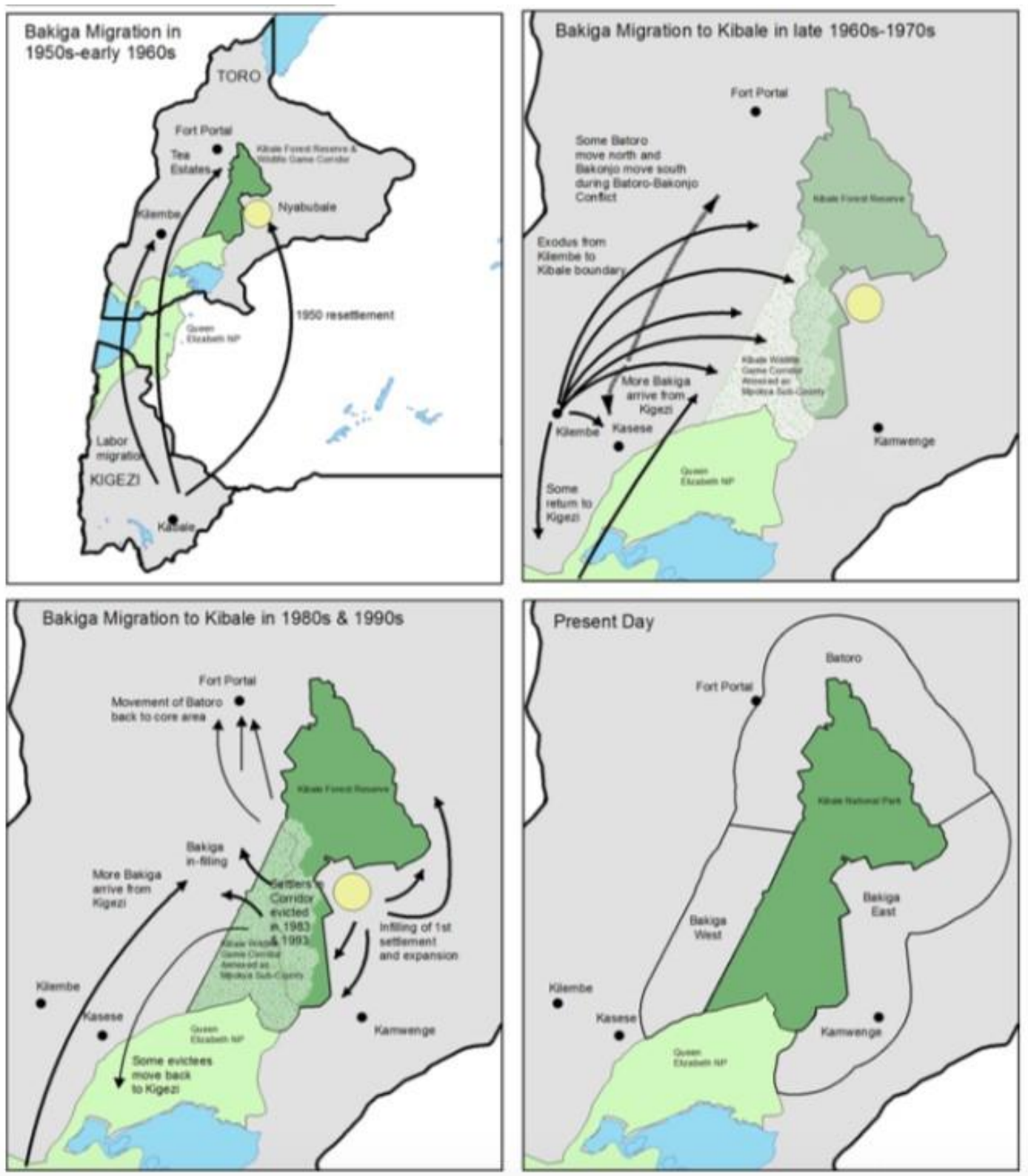

Taken from Hartter, et al., (2015).

\section{APPENDIX 4}

KNP park surroundings, taken from the study by MacKenzie, (2012). Although only four districts around KNP are Although only four districts are placed around KNP in the figure, there are five districts that share boundaries with the park, which are Bunyangabo, Kabarole, Kamwenge, Kasese and Kyenjojo. Although Bunyangabo district is not on the map, this district is located in the area where the silhouette of the map of Uganda where the KNP map is located coincides with the map of the districts. 


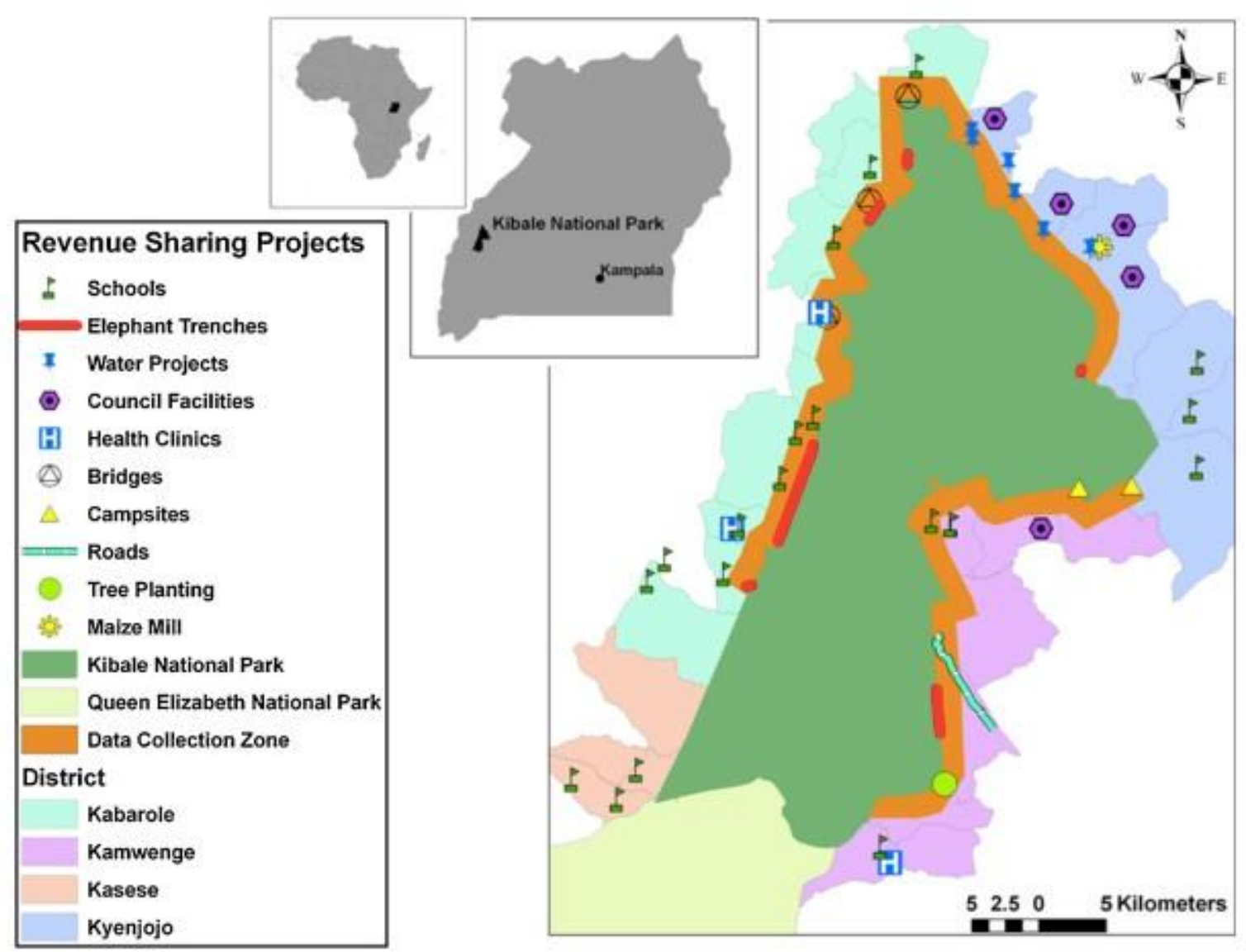




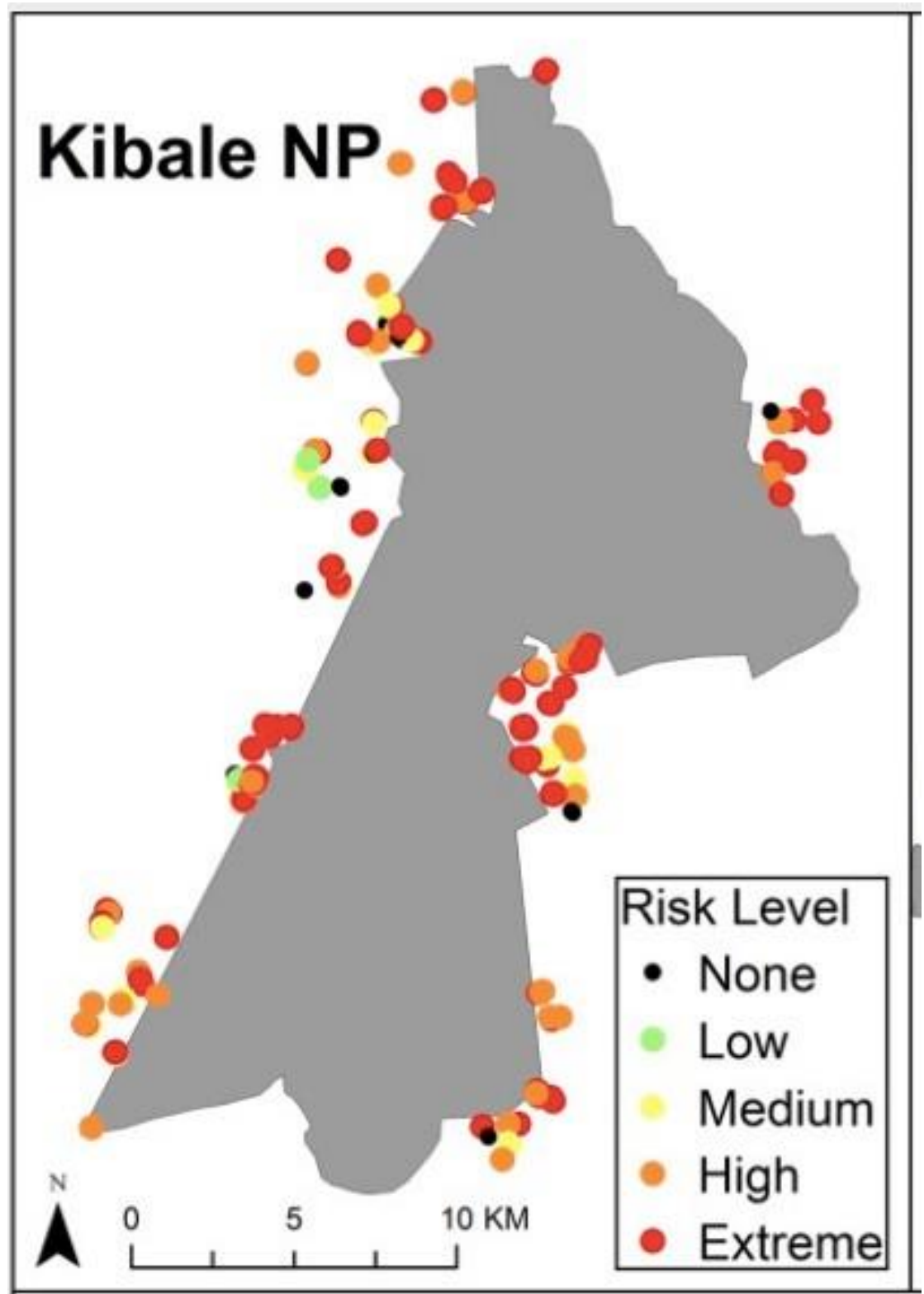

Taken from the study by Hatter, et al., (2016)

\section{APPENDIX 6}

\section{Other Strategies Used to Reduce Conflict Between Communities and Animals in KNP}

In addition to the previously stated strategies, other strategies noted to have been used in some places in Africa where there are conflicts between communities and wild animals, is through keeping wild animals at a distance with live fences of the exotic Mauritius shrub (Caesalpinia decapetala) which is used as a "living fence" to deter baboons, gorillas, wild pigs and elephants (Babaasa, et al., 2013). This tree has been planted in Kibale (Nadiope, personal communication, June 2018). Pre-soaked Mauritius thorn seeds are sown directly at $50 \mathrm{~cm}$ intervals in three rows, $30 \mathrm{~cm}$ apart (Schroth, et al., 2004). The resulting hedge is effective when established at these distances and when the branches are layered and intertwined by hand to form an animal-proof barrier (Babaasa, et al., 2013). 
However, as the Mauritius tree is not a species with a natural distribution in Africa, but an introduced species from regions such as China, Japan, Malaysia and India, it has been seen to cause problems in Africa, as it can have an invasive potential (Bryne, et al., 2011), and some places in Africa have already begun to develop experiences to manage and control this tree species due to the negative impacts it can generate on biodiversity and on productive systems, in addition to benefiting fire (Bryne, et al., 2011).

This species has come to be considered in some parts of Africa as one of the most invasive species, and has been identified as a species that can compromise conservation and production in agricultural fields (Mararakanye, et al., 2017). For example, this tree was declared in South Africa as an invasive species in 1983 (Bryne, et al., 2011).

According to this background, and that the tree is a melliferous species that can become established very close to places where bees are also used to help reduce the conflict between wild animals and communities, this interaction can generate major problems in the context of this conflict.

Another alternative that has been experimented with is to place red pepper chili baits, where a mixture is made with the chili peppers and elephant or cow dung, and the smell drives the elephants away, however, these baits have the problem that they are washed away with water and that the action is effective only if the wind is upwind against where the elephants come from since if not the smell will not reach them (Babaasa, et al., 2013; Shaffer, et al., 2019).

In the case of people working in parks, one of the techniques they use to scare away wild animals when they leave the park is to use persuasive shots, this is a method that has been traditionally used, however, in some places it is no longer a technique that works, since there are animals that do not feel intimidated with this technique (Babaasa, et al., 2013; Shaffer et al., 2019; Silajander et al., 2020).

A method that has also been used to try to decrease conflict has been through community monitoring systems (Shaffer, et al., 2019). Within the techniques used in the communities, shelters are built and fires are made to burn at the entrance. It usually involves shouting, hitting objects, throwing sticks or stones to scare the animals (Shaffer, et al., 2019). Shelters are used at night and/or when it rains. This method is effective against nocturnal animals such as buffalo, elephants, and wild pigs and diurnal animals such as primates. Animals will flee or avoid intensely guarded fields; therefore, guarding is labor intensive, which often restricts household participation in income-generating activities or keeps children away from school as they tend crops (Babasa, et al., 2013).

Parallel to community monitoring, the technique of chasing and/or herding wild animals is also used, in this technique some groups are organized within the community to scare the wild animals away from human settlements or cultivation areas, this method should have a high participation of the people of the community, especially people who have a high knowledge of the behavior of different animal species to avoid confrontations (Babaasa, et al., 2013).

Other mechanisms that have been tested have been through mechanisms that propose compensation schemes (Shaffer, et al., 2019), however, the experiences that have been had with some projects that have developed this mechanism in different places around parks in Africa, have had problems for its implementation due to corruption problems (Laudati, 2010). However, positive examples have also been found on how compensations can be effective, within what has been raised is that there must be transparency, fairness, realistic evaluations, clear standards, avoidance of corruption and local community participation (Gloriose, 2019). As part of the options that have also been suggested to be more successful in this measure, is the tax refund for farmers in frontline communities for damaged crops (Chege, et al., 2002).

Another mechanism that could be observed in the field visit that was made to the KNP environments, to reduce the conflict, was the construction of large ditches of at least 2 meters deep and more than two meters wide, ditches that in some cases can occupy a few hundred meters, in addition to this, it could also be observed that in a complementary way to these ditches, there is installation of places to make controlled fire for when there is nearby presence of wild animals (Nadiope, personal communication, June 2018).

In some of the places visited where these ditches were present, landslides were found, possibly caused by wild animals trying to get through. Among the problems that have been identified with the ditches is that they require relatively frequent maintenance, since landslides can occur due to soil erosion caused by 
water, wind and weather, as well as by the actions of wild animals in search of food or to move (Babaasa, et al., 2013).

Other options that have been used are traps to control certain animals (Shaffer et al., 2019), but they cannot be used in places where they can affect wild animals that have a higher social value, such as gorillas and chimpanzees, it is a control mechanism that is quite controversial to implement (Shaffer et al., 2019).

Electric fencing is a technique that has been used in some natural parks in Africa (Shaffer et al., 2019), it is an effective technique, however, installation and maintenance costs can become high, in many cases electricity is produced through solar panels. It has been found that in some cases the fence can be a barrier that can be overcome by some large mammals, so it has been reported that other complementary systems are needed (Babaasa, et al., 2013).

Iron meshes were made on some sites fencing with strong iron and iron mesh fencing, this can be effective, however, the costs are high. So they are used in mainly cash grazier sites ((Babaasa, et al., 2013; Shaffer, et al., 2019).

Landowners in areas where there has been conflict should try to be more accountable to local populations by prioritizing conflict mitigation, equipping local villagers with modern conflict relief techniques so that existing or more traditional mitigation measures go augmented (Matseketsa, et al., 2019). Likewise when it is detected that some of the barriers that prevent wild animals from leaving the protected area have been damaged, quick and constant repairs should be made, which will go a long way in reducing the frequency and amount of damage by wild animals (Matseketsa, et al., 2019).

Another possibility that has been identified to reduce conflicts with small and medium-sized wild animals, such as primates, are the strategies that some farmers have used, such as the use of radios, bells or gunshots to make noise (Silajander et al., 2020). In other cases they have guard dogs (Silajander, et al., 2020).

Even despite the decline in elephants, some control alternatives that are still used with some elephants in Africa is lethal control as it is often considered a cheap and cost-effective method of reducing wildlife conflict, which may explain its popularity among some governments (Hodgson, et al., 2020).

Other issues that have also been developed around how to reduce conflict as it increases community tolerance are related to management techniques that can provide additional benefits to local communities, such as generating income from trophy and sport hunting (Hodgson, et al., 2020). 